\title{
Pharmacotherapy in Anaemia of Pregnancy: Comparison of Oral Ferrous Sulphate, Intravenous Iron Sucrose and Intravenous Ferric Carboxymaltose
}

\author{
HAFSA MUHAMMAD ${ }^{1}$, ANILA ANSAR ${ }^{2}$, SAAD ANSAR ${ }^{3}$, ISHTIAQ AHMAD ${ }^{4}$, ANSAR LATIF \\ ${ }^{1}$ Department of Pharmacology, University of Health Sciences, Lahore \\ ${ }^{2}$ Professor \& Head of Department of Obstetrics \& Gynaecology, Khawaja Safdar Medical College, Sialkot \\ ${ }^{3}$ House Officer, Mayo Hospital, Lahore \\ ${ }^{4}$ Assistant Professor of Surgery, Khawaja Safdar Medical College, Sialkot \\ ${ }^{5}$ Associate Professor \& HOD, Department of Surgery, Khawaja Muhammad Safdar Medical College, Sialkot. \\ Correspondence to Dr. Hafsa Muhammad, Email: hafsaishtiak@gmail.com, cell 03008612060.
}

\begin{abstract}
Aim: To analyse the outcome of oral and intravenous therapy of iron preparations in treating anaemia in pregnant women.

Study Design: Prospective Study.

Place and duration of study: Department of Pharmacology and department of Gynaecology and obstetrics, Khawaja Muhammad Safdar Medical College, Sialkot from May 2020 to July 2021.

Methods: Between May 2020 and July 2021; A total of 1200 patients presenting to obstetric department with anaemia were included in the study after fulfilling inclusion criteria. Pregnant patients with haemoglobin level 7$8 \mathrm{gm} / \mathrm{dl}$ at $24^{\text {th }}$ week of gestation were included in the study. The therapy was started on $24^{\text {th }}$ week of gestation. The haemoglobin levels were determined at $24^{\text {th }}$ week and then at $37^{\text {th }}$ week of gestation. The increase in the haemoglobin level was then determined. Serum ferritin levels were done at $37^{\text {th }}$ week of gestation.

Results: It was observed that there was an increase in the haemoglobin level after all the treatment regimes. The increase in haemoglobin in the group $B$ and $C$ was statistically significant with $P$ value of $<0.001$ when compared with the group A. However, no statistical significant difference was observed between group B and group C.

Conclusion: The haemoglobin and serum ferritin level were significantly increased in the subjects after oral ferrous sulphate, however parenteral formulation are more effective in noncompliant patient where quick improvement in haemoglobin levels are to be achieved.

Keywords: Anaemia, pregnancy, iron deficiency, pharmacotherapy
\end{abstract}

\section{INTRODUCTION}

Iron deficiency anaemia is the most common type of anaemia globally. Anaemia affects $40 \%$ of pregnancies worldwide and is associated with an increased risk of perinatal morbidity and mortality including risk of preterm birth and low birth weight. The iron status of infants is linked to that of the mother. Infants that are born to anaemic women are at an increased risk of developing iron deficiency anaemia in the early years of life ${ }^{1}$.

The prevalence of iron deficiency anaemia in Pakistani women is between $30-60 \%$. In Pakistan maternal mortality rate of 276 per 100,000 live births has been reported along with the perinatal mortality of 75 per 1000 pregnancies. Iron deficiency anaemia also leads to the high numbers of small for gestational age births and low birth weight babies. That adds to considerable perinatal morbidity and mortality ${ }^{2}$.

In developing countries, demographic, cultural, and socioeconomic factors could affect the occurrence of anaemia in pregnancy. There is a significant association between maternal anaemia and adverse perinatal outcomes such as placenta previa, placental abruption, preterm birth, and low birth weight ${ }^{3}$. The causes of iron deficiency anaemia are multifactorial, but the primary cause

Received on 14-04-2021

Accepted on 17-08-2021 is iron deficiency secondary to chronic inadequate dietary intake and menstruation, heightened by the physiologic demands of the fetus and maternal hemodilution \& volume expansion during pregnancy 4 .

Oral iron supplementation is the first choice of treatment for iron deficiency anaemia because of easy availability and cost affectivity at all primary health centres. Ferrous salts are preferred over ferric salts by the world health organisation due their effectiveness, better absorption, and low cost. Therefore, ferrous sulphate was used in the present study. Parenteral iron preparations are useful in cases noncompliant to oral iron. Intravenous iron sucrose and ferric carboxymaltose preparation are effective safe for single large dose with high availability for erythropoiesis ${ }^{5}$. No study in this regard has been done in our hospital setting so we wanted to see the outcome of different modalities of treatment.

Our study aimed to unravel the difference in some of the haematological parameters after oral and parenteral iron treatments.

\section{PATIENTS AND METHODS}

Iron deficiency anaemia is the most common type of anaemia. After approval from ethical committee, this study was designed to compare the effect of ferrous sulphate, iron sucrose and ferric carboxymaltose on the pregnant females of Sialkot. In this study, we compared the rise in the haemoglobin levels and serum ferritin levels after 
treating pregnant females with ferrous sulphate, iron sucrose and ferric carboxymaltose.

Pregnant patients with haemoglobin level $7-8 \mathrm{gm} / \mathrm{dl}$ at $24^{\text {th }}$ week of gestation were included in the study. The therapy was started on $24^{\text {th }}$ week of gestation. The haemoglobin levels were determined at $24^{\text {th }}$ week and then at $37^{\text {th }}$ week of gestation. The increase in the haemoglobin level was then determined. Serum ferritin levels were done at $37^{\text {th }}$ week of gestation.

Patients having concomitant hepatitis, diabetes and gastrointestinal ailments like diagnosed acid peptic disease, inflammatory bowel disease, irritable bowel disease or abdominal helminthiasis were excluded from the study. Those not reported with investigations at $37^{\text {th }}$ week were also dropped from the study. Those patients having bleeding disorders, placenta previa and those who suffered vaginal bleeding during the study period, having threatened abortions were are not included in the data.

This study was done after the permission of the ethical committee of the college. It was a prospective study that was done after taking informed consent of the patients and their families. The sample was calculated with formula. Total 600 patients participated (completed) in the study. The patients were assigned randomly into three groups with $n=400$, while keeping in mind the socioeconomic status. The patients at 24 weeks of gestation and haemoglobin level of $7-8 \mathrm{~g} / \mathrm{dl}$ were included in the study. The patients were followed regularly during antenatal check up till 37 weeks of gestation when their haemoglobin levels and serum ferritin levels were checked. Total iron requirement was calculated by the formula:

Required iron dose $(\mathrm{mg})=(2.4 \times($ target $\mathrm{Hb}$-actual $\mathrm{Hb}) \times$ pre-pregnancy weight $(\mathrm{kg}))+1000 \mathrm{mg}$ for replenishment of stores.

Group A was administered with tablet ferrous sulphate $65 \mathrm{mg}$ twice daily, Group B was administered with injection iron sucrose (Venofer available in the hospital formulary) $200 \mathrm{mg}$ in $100 \mathrm{ml}$ normal saline as infusion over $20 \mathrm{~min}$ at 25 weeks, 29 weeks, and 34 weeks of gestation. Group C was administered intravenous $1000 \mathrm{mg}$ of ferric carboxymalt. Tablet albendazole $400 \mathrm{mg}$ was given at the beginning of the study to all pregnant women.

Sample collection: At the start of the study haemoglobin levels were done by obtaining the venous blood sample from the antecubital vein. Haemoglobin levels were done by haematology analyser. At the time of the antenatal visit at term, blood of the patient was again drawn from the antecubital vein under strict aseptic technique. $1.5 \mathrm{ml}$ of blood was collected in EDTA vacutainer and $2 \mathrm{ml}$ of blood was put in the non EDTA clot activator vacutainers. The blood in the non EDTA vacutainers was centrifuged at 3000 rotations per minute in a centrifuge tube to separate serum. Serum was carefully aspirated with a micropipette and collected and labelled in the small plastic tubes. Haemoglobin estimation was done by haematology analyser and serum ferritin levels were done by serum ferritin ELISA kit using sandwich technique.

Data analysis: Data was analysed using Graph Pad version 6. Mean and standard deviation was given for quantitative variables. One way analysis of variance (ANOVA) followed by post hoc tukey test to determine the significant difference between the three groups. P value < 0.05 was considered statistically significant.

\section{RESULTS}

Table I: Demographic data

\begin{tabular}{|l|l|}
\hline $\begin{array}{l}\text { Total patients enrolled in study fulfilling inclusion } \\
\text { criteria }\end{array}$ & $1200(100 \%)$ \\
\hline Group A- oral Ferrous Sulphate & 400 \\
\hline Group B- Intravenous Iron Sucrose & 400 \\
\hline Group C- Intravenous Ferric Carboxymaltose. & 400 \\
\hline
\end{tabular}

Mean values with standard deviation is shown as follows.

Table II: Mean \pm SD for increase in haemoglobin $(\mathrm{gm} / \mathrm{dl})$

\begin{tabular}{|l|l|l|l|}
\hline & $\begin{array}{l}\text { Group A } \\
(\text { Mean } \pm \text { SD) }\end{array}$ & $\begin{array}{l}\text { Group B } \\
(\text { Mean } \pm \text { SD) }\end{array}$ & $\begin{array}{l}\text { Group C } \\
(\text { Mean } \pm \text { SD) }\end{array}$ \\
\hline $\begin{array}{l}\text { Increase in } \\
\text { haemoglobin } \\
(\mathrm{gm} / \mathrm{dl})\end{array}$ & $2.286 \pm 0.58$ & $3.600 \pm 0.48^{* * *}$ & $3.714 \pm 0.45^{* * *}$ \\
& & & \\
\hline$* * * \mathrm{P}$ value < 0.001 when compared with group A
\end{tabular}

Figure 1: Graphical presentation of increase in haemoglobin

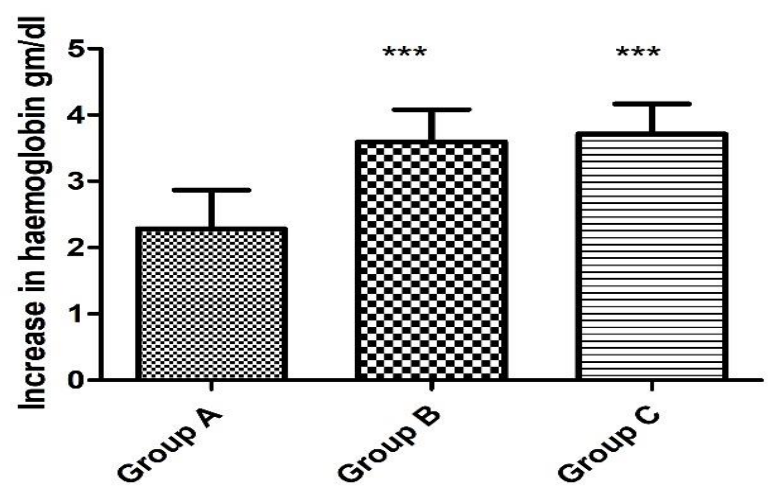

Serum ferritin level: There was a significant increase in the serum ferritin level in group $B$ and group $C$ with $P$ value of $<0.001$. No significant difference was seen between group B and group C.

Table III : Mean \pm SD of serum ferritin level $(\mathrm{ng} / \mathrm{ml})$
\begin{tabular}{|l|l|l|l|}
\hline & $\begin{array}{l}\text { Group A } \\
\text { (Mean } \pm \text { SD) }\end{array}$ & $\begin{array}{l}\text { Group Bean } \pm \text { SD) } \\
(\text { Meear }\end{array}$ & $\begin{array}{l}\text { Group } \\
\text { C (Mean } \pm \text { SD) }\end{array}$ \\
\hline $\begin{array}{l}\text { Serum ferritin } \\
\text { level (ng/ml) }\end{array}$ & 32.86 & $43.14^{* * *}$ & $43.57^{* * *}$ \\
\hline
\end{tabular}

${ }^{* * *}=\mathrm{P}$ value $<0.001$ when compared with group $\mathrm{A}$

Figure 2: Graphical presentation of serum ferritin levels at 37 weeks of gestation

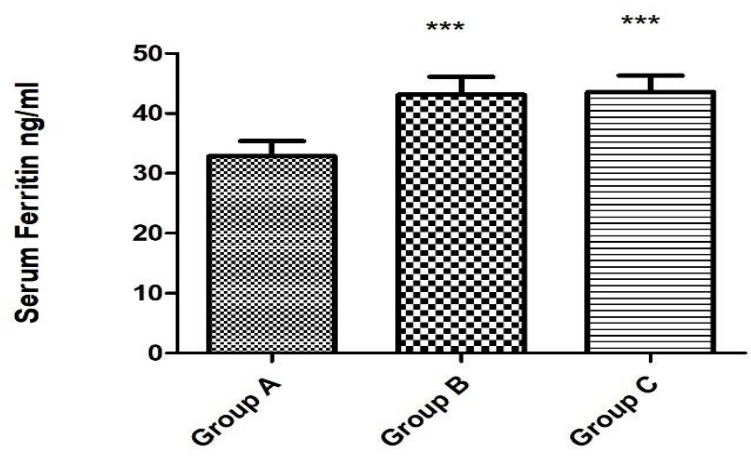




\section{DISCUSSION}

Severe iron deficiency with anaemia is frequent among pregnant women in developing countries such as Pakistan and especially in the rural areas. Iron prophylaxis in pregnancy treats the deficiency and prevents maternal and fetal morbidity and mortality. The method of haematological parameter measurement, blood sample source and techniques for the storage and analysing the samples can affect the measured haemoglobin concentration and serum ferritin levels. Same remarks have been given in the study by Qassim $A$ et $\mathrm{al}^{6}$ and Habib MA et $\mathrm{al}^{7}$ In this study we tried to use simple and standard techniques to keep bias on the minimal level.

Oral iron supplementation is the first choice of treatment for iron deficiency anaemia that is diagnosed at an early gestation and for the prophylaxis of patients with normal haemoglobin levels because of their efficacy and easy availability. Ferrous salts are preferred over ferric salts by the WHO due their effectiveness, better absorption, and low cost. Therefore, ferrous sulphate was used in the present study. Patients of group A were treated twice daily with $65 \mathrm{mg}$ ferrous sulphate and this treatment group required regular visits and we were also concerned about their compliance and oral bioavailability. These findings are consistent with those of study by Khalid R et al ${ }^{8}$. We found that the use of intravenous iron during pregnancy is associated with significant improvements in haematological parameters. Intravenous iron was generally well tolerated and ensured better bioavailability and compliance of the patients as the intravenous iron preparations were given under the supervision of researchers and health care staff in a clinical setting. To improve the haematological parameters in the patients of advanced chronic kidney disease the researchers conducted a research to compare oral iron sulphate with the parenteral iron preparations and it was concluded that the parenteral iron treatments were more effective in improving the haemoglobin and serum ferritin level with minimal side effects; same as shown by Bhatt $A$ et $\mathrm{al}^{9}$. These finding can be attributed to the fact that most of the patients have a poor compliance. Oral iron bioavailability is also affected by food intake like phytates and caffeine.

Based on the findings of one review, no single preparation of IV iron appeared to be superior than the other. A study conducted on the outcomes of different oral and intravenous iron formulations suggested that almost all the iron preparations are effective if used properly ${ }^{10}$.

Intravenous iron therapy significantly increased the haematological parameters after the treatment when compared with oral iron treatment regime in paediatric population ${ }^{10}$. This result was consistent with our study.

Further research is needed to determine the optimal dosing and administration regimens for iron therapy. The current IV iron preparation of choice in pregnancy is largely determined by patient doctor personal choices, cost and convenience around administration. Favourable properties of ferric carboxymaltose including the ability to administer a high dose in a single infusion over a short period of time has led to its increasingly common use in obstetric patients.

Due to the limitation of the budget resources we were unable to do the other haematological parameters. The intake of oral iron or the intravenous iron formulations is largely affected by the socioeconomic factors. In the future a study including a larger number of pregnant females should be done over longer period of time to assess postpartum haematological parameters.

\section{CONCLUSION}

The haemoglobin and serum ferritin level were significantly increased in the subjects after oral ferrous sulphate, however parenteral formulation are more effective in noncompliant patient where quick improvement in haemoglobin levels are to be achieved.

\section{Conflict of interest: Nil}

\section{REFERENCES}

1. DelRosso, L.M., D.L. Picchietti, and R. Ferri, Comparison between oral ferrous sulfate and intravenous ferric carboxymaltose in children with restless sleep disorder. Sleep, 2021. 44(2): p. zsaa155.

2. Rogozińska, E., et al., Iron preparations for women of reproductive age with iron deficiency anaemia in pregnancy (FRIDA): a systematic review and network meta-analysis. The Lancet Haematology, 2021. 8(7): p. e503-e512.

3. Cirillo, L., et al., Ferric carboxymaltose vs. ferrous sulfate for the treatment of anemia in advanced chronic kidney disease: an observational retrospective study and cost analysis. Scientific reports, 2021. 11(1): p. 1-8.

4. Haemoglobin concentrations for the diagnosis of anaemia and assessment of severity. 2011, World Health Organization

5. ADAJI, J.A., Daily Versus Twice Daily Dose of Ferrous Sulphate Supplementation in Pregnant Women: A Randomised Clinical Trial. Faculty of Obstetrics and Gynaecology, 2016.

6. Qassim A et al., Safety and efficacy of intravenous iron polymaltose, iron sucrose and ferric carboxymaltose in pregnancy: A systematic review. Australian and New Zealand Journal of Obstetrics and Gynaecology, 2018. 58(1): p. 22-39.

7. Habib MA., et al., Prevalence and determinants of iron deficiency anemia among non-pregnant women of reproductive age in Pakistan. Asia Pacific journal of clinical nutrition, 2018. 27(1): p. 195-203.

8. Khalid R. et al., Risk factors for Anemia in Pregnant Women in a rural area of Bahawalnagar Pakistan-a Descriptive Cross Sectional Study.Pak J Med Health Sci, 2017. 11(4): p. 12381242.

9. Bhatt A, N. Vinayak, and N. Acharya, Role of intravenous iron sucrose in comparison to oral ferrous sulfate for prophylaxis of anemia in pregnant women. Journal of Datta Meghe Institute of Medical Sciences University, 2020. 15(1): p. 12.

10. Kriplani, A., et al., Intravenous iron sucrose therapy for moderate to severe anaemia in pregnancy. The Indian journal of medical research, 2013. 138(1): p. 78. 